\title{
IMPLANTAÇÃO DE SISTEMAS DE SIMULAÇÃO E OTIMIZAÇÃO DE LOGÍSTICA POR MEIO DE MODELOS DE PROGRAMAÇÃO LINEAR E LÓGICA FUZZY, EM TEMPO REAL*
}

Antônio César de Araújo Freitas ${ }^{1}$ Murilo Ribeiro Ferreira²

\section{Resumo}

As empresas de mineração têm desafios logísticos em sua operação no dia a dia, visto o crescente volume de minério movimentado nas Usinas e Portos e pressão crescente por resultados operacionais que se traduzem na busca contínua por níveis superiores de produtividade. A tecnologia de automação dos processos produtivos e de máquinas evoluiu muito na última década, entretanto o processo da logística nos pátios de matéria prima e produtos apresenta baixo nível de automação e é baseado em informações verbais e observações visuais a respeito do nível de estoques e disposição dos materiais nas pilhas e áreas dos pátios de manuseio. Em um processo tão complexo, pequenas decisões da operação no dia a dia, que podem variar de acordo com o operador, supervisor ou turno de operação, podem influenciar a produtividade diretamente, afetando indicadores como horas paradas e deslocamento de máquinas por tonelada expedida, afetando dessa forma custos significativos na operação de uma usina ou porto. Este trabalho tem por objetivo então descrever as técnicas utilizadas para modelar os desafios de logística nos pátios de minério, descrevendo sistemas de otimização utilizados com apresentação de resultados em projetos como o de Carajás, planta da VALE que é atualmente a maior mina de minério de ferro do mundo, abordando a redução de deslocamento de máquinas, diminuição da exposição ao risco de colisão e redução de paradas.

Palavras-chave: Otimização; Logística; Simulação; Pátios de minério.

\section{LOGISTICS OPTIMIZATION AND SIMULATION IN REAL TIME FOR STOCKYARD OPERATIONS WITH LINEAR PROGRAMMING AND FUZZY LOGIC \\ Abstract}

Mining companies have logistical challenges in their daily operations, as the increasing volume of ore and increasing pressure on the operating results that takes to the continuous search for higher levels of productivity. The technology automation of production processes and machinery has evolved in the last decade, however the process of logistics in the stockyards of raw materials and products has a low level of automation and is based on verbal information and visual observations. In such a complex process, small decisions of the daily operation, which may vary according to the operator, supervisor or shift operation, can influence productivity directly and affect indicators such as downtime and offset machines per ton shipped, affecting thus significant costs in operating a plant or port. This work aims then describe the techniques used to model the logistics challenges in the stockyards, describing optimization systems used with presentation of results achieved in projects such as Carajas from VALE, the largest iron ore mine in the world, addressing reduction in travel distance for machines, decreased exposure to the risk of collision and reducing stoppages.

Keywords: Logistics; Simulation; Mining stockyard.

Engenheiro Eletricista, Diretor da TSA, Belo Horizonte, Minas Gerais, Brasil.

2 Engenheiro de Automação, Gerente de Pesquisa e Desenvolvimento da TSA,Belo Horizonte, Minas Gerais, Brasil.

* Contribuição técnica ao $18^{\circ}$ Seminário de Automação e TI Industrial, 23 a 26 de setembro de 2014, São Paulo, SP, Brasil. 


\section{INTRODUÇÃO}

O setor de mineração é de suma importância para a economia brasileira. O país também é importante no cenário internacional tanto por sua enorme produção mineral quanto por suas grandes reservas. No caso do minério de ferro, que é o mineral de maior produção no país, o Brasil possui a quinta maior reserva de minério de ferro e é o segundo maior produtor mundial conforme dados do Instituto Brasileiro de Mineração [1].

O processo de exploração do minério de ferro envolve uma complexa alocação de recursos como frentes de lavra, usinas de beneficiamento, pátios de estocagem, correias transportadoras, maquinário e mão de obra. Neste cenário um grande número de decisões devem ser tomadas rotineiramente de forma a conduzir o processo de mineração, havendo tanto decisões que abordam toda a cadeia de produção até decisões que levam em conta pontos específicos de uma planta de mineração.

Um dos elementos da cadeia de produção da indústria da mineração é o pátio de estocagem. Em um pátio de estocagem um ou mais produtos de minérios são armazenados em pilhas a espera de seu carregamento para distribuição em clientes finais ou portos. A alocação de produtos no pátio envolve um conjunto de operações que impactarão nos custos e volume de material expedido por uma mina e na qualidade deste minério.

Um dos problemas que surgem na indústria da mineração consiste em determinar a alocação e recuperação de produtos em um ou mais pátios de estocagem de forma a atender demandas de expedição definidas por uma oferta de trens a serem carregados, de forma a respeitar as restrições operacionais do processo de produção de minério e do maquinário e mão de obra destes pátios, buscando reduzir os custos desta atividade e atender as metas de qualidade do material enviado.

O objetivo deste trabalho é apresentar a construção de um sistema web que trata do problema de otimização do gerenciamento de pátios de estocagem de minério como um problema de otimização matemática, inspirado na operação dos pátios de estocagem do complexo minerador de Carajás, no estado brasileiro do Pará.

\section{MATERIAIS E MÉTODOS}

\subsection{Pesquisa Operacional Aplicada a Indústria da Mineração}

Conforme definido em [2] a Pesquisa Operacional, ou simplesmente $P O$, consiste de um processo científico com fim de auxiliar no processo de tomada de decisão para a resolução de problemas fazendo uso de métodos matemáticos e algorítmicos. Basicamente, busca-se definir para um dado problema a alocação ótima de recursos que resolvam tal problema.

O próprio trabalho de [2] classifica as aplicações de Pesquisa Operacional de acordo com o nível de tomada de decisão:

- Nível estratégico: decisões de escopo amplo e de horizontes de longo prazo, com foco sobre o estabelecimento de políticas e o desenvolvimento de recursos necessários aos objetivos da organização. No contexto da mineração, tais decisões envolvem, por exemplo, a expansão de capacidade produtiva [3], modelo de simulação para determinar os blocos de minas a serem explorados [4], e a análise de riscos de investimentos [5].

\footnotetext{
* Contribuição técnica ao $18^{\circ}$ Seminário de Automação e TI Industrial, 23 a 26 de setembro de 2014 , São Paulo, SP, Brasil.
} 
- Nível tático: decisões de escopo mais estreito e de horizontes de médio prazo, com foco sobre a alocação e utilização adequadas dos recursos providos no nível estratégico. No contexto da mineração, tais decisões envolvem, por exemplo, o planejamento de produção em minas [6], ferrovias [7], e portos [8].

- Nível operacional: decisões de curto prazo relacionadas à organização do trabalho dos recursos, de modo a alcançar os objetivos fixados no nível tático. No contexto da mineração, tais decisões envolvem, por exemplo, a alocação de equipamentos de carga [9], o controle do deslocamento de trens em ferrovias [10], e a programação da produção em pátios de estocagem [11], e portos [8].

Conforme [12], a literatura de aplicações de PO na indústria da mineração podem ser organizadas de acordo com seu nível funcional:

- Minas: nesta dimensão funcional encontram-se os trabalhos relacionados essencialmente às minas, como o de definição de fluxos em minas [13] e de programação integrada de produção das minas [14].

- Logística: trabalhos relacionados a otimização das operações em ferrovias.

- Porto: cabe destacar trabalhos relacionados como a alocação de recursos em portos [8].

O problema de otimização associado ao gerenciamento de pátios é um problema de nível operacional em que as decisões de utilização de máquinas nos pátios estão associados à mina, e por isso são tratados em tempo real, o que diferencia este sistema das abordagens tradicionais de otimização e simulação que consideram normalmente cenários "off-line" .

\subsection{Pátios de Estocagem de Carajás}

O problema de otimização de operação de máquinas em um conjunto de pátios de estocagem é inspirado no Sistema Norte da Companhia Vale do Rio Doce, no complexo minerador de Carajás [1]. A figura abaixo esquematiza simplificadamente o problema:

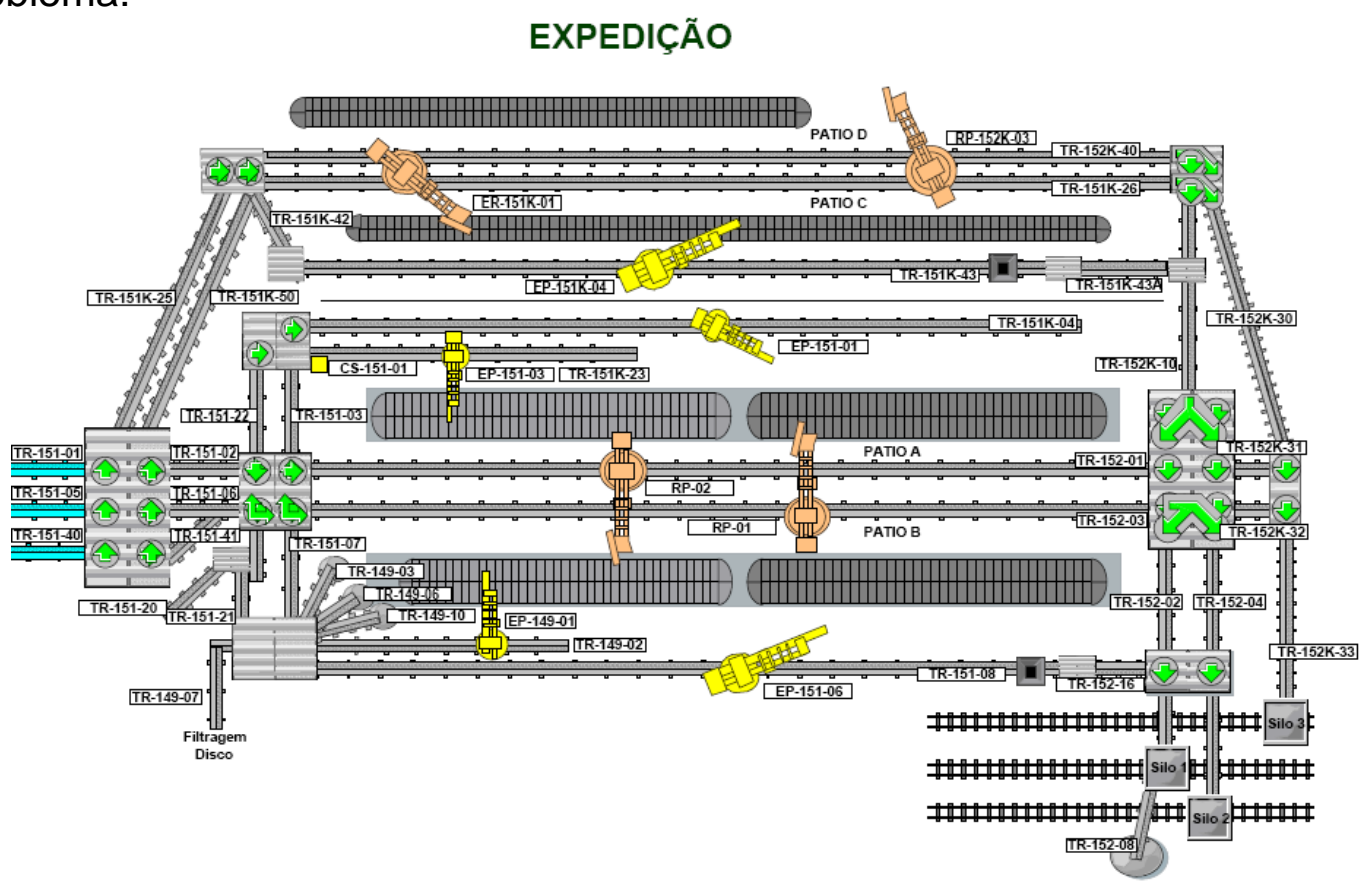

Figura 1: Esquematização dos pátios de estocagem de Carajás

* Contribuição técnica ao $18^{\circ}$ Seminário de Automação e TI Industrial, 23 a 26 de setembro de 2014, São Paulo, SP, Brasil. 
É importante ressaltar que o processo de estocagem de minérios a ser descrito, embora esteja fortemente inspirado no complexo minerador de Carajás, pode ser aplicado de forma geral a qualquer conjunto de pátios de estocagem de minério de ferro.

O problema em questão não aborda todas as estruturas produtivas do complexo minerador, focando apenas em 4 pátios de estocagem, nas 5 empilhadeiras, 3 recuperadoras de minério e 1 empilhadeira-recuperadora.

O Conjunto de usinas enviam para os pátios através de uma rede de correias transportadores 3 tipos de produtos diferentes conhecidos como Sinter Feed, Pellet Feed e Granulado. Cada um desses produtos são avaliados por um conjunto de parâmetros químicos e físicos, conhecidos também como parâmetros de qualidade. Ao longo do processo de produção os materiais gerados podem apresentar uma variação de valores para esses parâmetros, em decorrência principalmente da qualidade do material que alimenta as usinas e de variações nas condições climáticas. Conforme os valores desses diversos parâmetros uma função de avaliação pode ser aplicada e uma nota dada a cada produto gerado de forma a caracterizá-lo de forma sucinta.

Os diversos produtos gerados e transportados através das correias transportadoras são destinados as máquinas empilhadeiras. Tais máquinas apresentam características de movimentação e capacidade específicas e conhecidas e empilham o material nas áreas dos pátios conforme decisão do operador da máquina em questão e do controlador de qualidade das áreas.

Após o material ser empilhado em uma dada área, em algum momento será definido a recuperação.

O material recuperado é destinado a um dos silos que compõe o sistema e por fim carregado via modal ferroviário para o porto em São Luis- MA.

\subsection{Problema de Otimização de Operação de Pátios de Estocagem}

As decisões que envolvem o gerenciamento de pátio definem:

- Áreas em que as empilhadeiras e recuperadoras irão operar ao longo de um horizonte de tempo.

- O volume a ser empilhado e/ou recuperado por cada máquina em cada área de pátio que ela for operada.

- $O(s)$ silo(s) de destino do material recuperado para a composição das demanda.

Foi construído modelo de programação linear inteira mista que representa matematicamente o problema de otimização do gerenciamento de pátio de estocagem de minérios. Neste modelo matemático tem-se como objetivo a minimização de custos de operação dos pátios representado por:

- Reduzir deslocamento das máquinas de empilhamento e recuperação;

- Minimizar desvios em relação a demanda em termos de quantidade e qualidade;

- Reduzir movimentos de giros de máquinas que podem operar em dois pátios;

- Reduzir mistura de minérios com especificações de qualidades diferentes nas pilhas de minérios nas áreas dos pátios.

O modelo construído leva em conta as restrições operacionais do processo de estocagem:

- Capacidade, em unidades de massa, de recuperação e/ou empilhamento das máquinas do pátio;

* Contribuição técnica ao 18Seminário de Automação e TI Industrial, 23 a 26 de setembro de 2014, São Paulo, SP, Brasil. 
- Pátios e áreas em que cada máquina pode ser utilizada;

- Áreas que cada produto pode ser empilhado;

- Capacidade, em unidades de massa, dos silos e transportadores;

- Tempo de residência de estocagem dos produtos;

- Não sobreposição de máquinas que compartilhem mesmo trilho de deslocamento;

- Capacidade de estocagem de cada uma das áreas.

Traçado um cenário utilizando informações da previsão de produção das usinas, estoque inicial das áreas e previsão de demanda a serem atendidas é possível instanciar o modelo matemático e, utilizando de algoritmos para resolução de problemas de programação inteira linear, definir operação ótima dos pátios levando em conta as restrições e os objetivos previamente descritos.

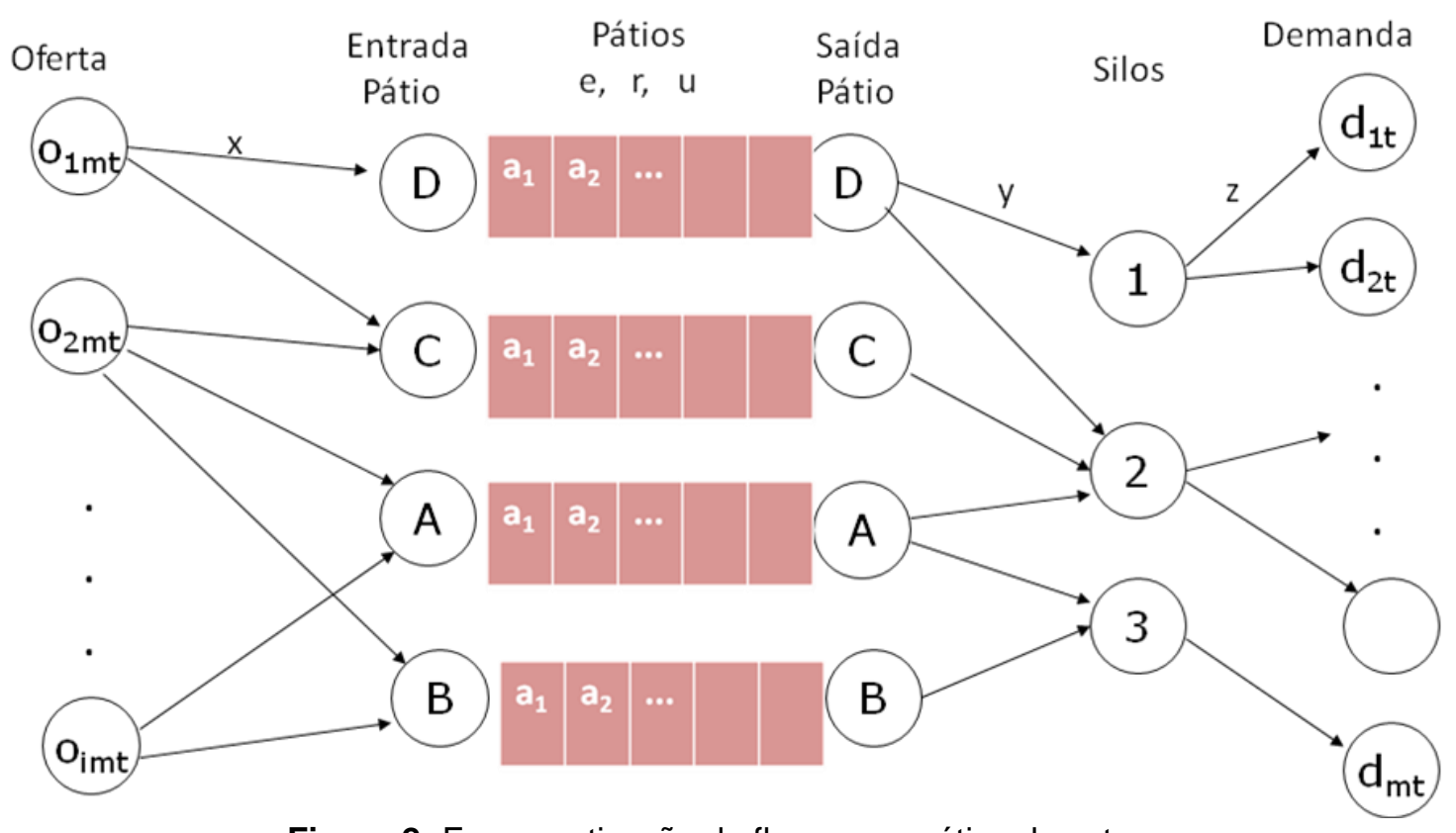

Figura 2: Esquematização de fluxos nos pátios de estocagem

\subsection{Sistema de Gerenciamento de Pátios}

A partir da construção do modelo matemático e do ferramental para resolvê-lo, foi construído um sistema de acesso via web para que seja possível inserir as informações de instanciação do modelo e recuperar seus resultados de forma a serem aplicados na rotina de controle dos pátios.

O sistema contém os dados básicos de configuração dos pátios para o preenchimento de restrições operacionais e permite que tais informações sejam editadas pelo usuário.

Para a criação de uma nova simulação é necessário inserir os seguintes dados para a simulação:

- Horizonte de tempo para otimização, ou seja, número de períodos que podem ser definidos em horas, turnos, dias, etc.;

- Parâmetros de qualidade que serão considerados;

- Previsão de produção das usinas, em termos de volume e qualidade de cada produto;

- Posição inicial das máquinas;

* Contribuição técnica ao 185eminário de Automação e TI Industrial, 23 a 26 de setembro de 2014, São Paulo, SP, Brasil. 
- Restrições das máquinas: capacidade, velocidade de deslocamento e giro, pátios e áreas que poderão operar;

- Estoque inicial das áreas dos pátios;

- Previsão de demanda de produtos em termos de quantidade e qualidade.

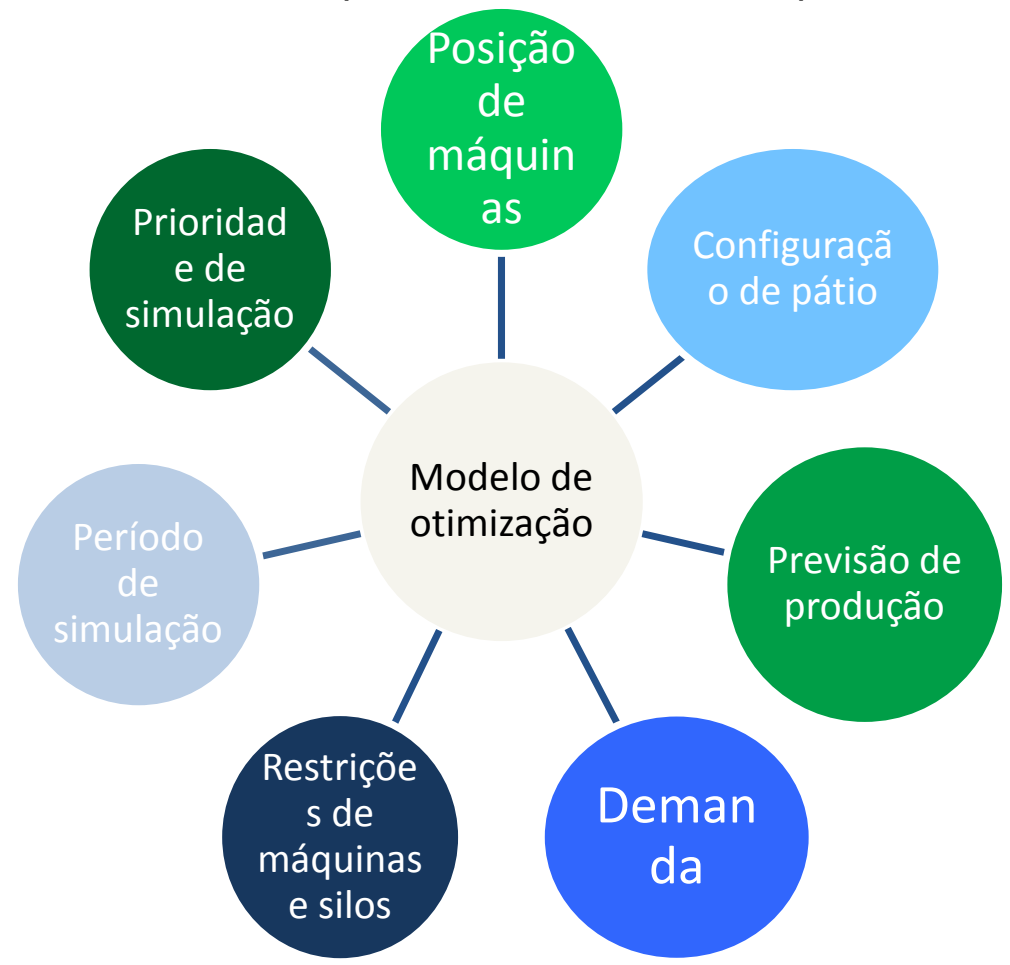

Figura 3: Conjunto de dados a serem inseridos para geração de modelo matemático

É importante ressaltar que em um sistema de produção de minério a previsão de produção nem sempre é assertiva, principalmente em termos de qualidade. Dessa forma o modelo de otimização é instanciado com base em um conjunto de informações de produção que em tempo real podem estar diferentes. Apesar do potencial de incerteza nos resultados da otimização, observa-se que no ambiente real essas diferenças não reduzem o potencial de ganho do modelo.

Além disso, o sistema apresenta um módulo de tracking que revisa a qualidade automaticamente, calculando a movimentação do material desde os pontos de coleta até o pátio.

* Contribuição técnica ao $18^{\circ}$ Seminário de Automação e TI Industrial, 23 a 26 de setembro de 2014, São Paulo, SP, Brasil. 


\subsection{Arquitetura da Solução}

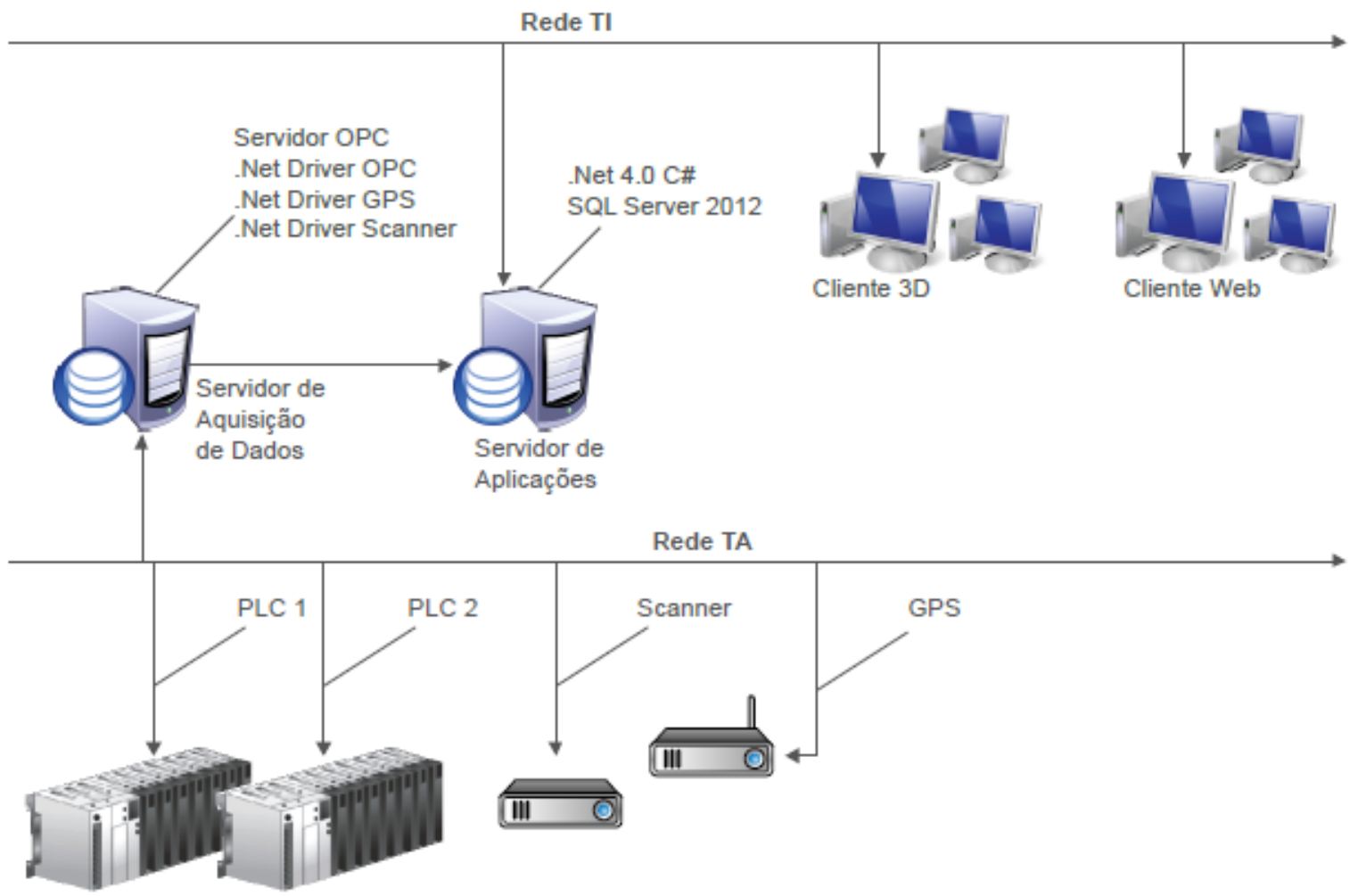

Figura 4 - Arquitetura típica do Sistema

\subsection{Principais Desafios e Problemas do Sistema de Gerenciamento de Pátio}

O principal desafio do projeto era viabilizar um sistema de gerenciamento de Pátios em tempo real para um cenário muito complexo, considerando que temos milhões de toneladas movimentadas por ano nos pátios citados neste trabalho, sendo que a logística é afetada diariamente por indisponibilidade de equipamentos, alteração de ritmo de produção, alteração de demanda do porto, variação de produtos e qualidades, variação da Mina, entre outros fatores. Verificamos que existiam uma série de sistemas no mercado, normalmente feitos sob encomenda, com o objetivo de otimizar a logística da cadeia de mineração, mas todos eles, dado o volume de informações e diversidades destas fontes de informação, são construídos para simular cenários de médio e longo prazo e não são capazes de tomar decisões em tempo real.

No início do projeto o desafio foi colocado nestes termos, tanto que foi uma contratação de risco em que a TSA comprometia-se com os resultados esperados pelo cliente, sob risco de não receber nenhum centavo por 2 anos de trabalho, tudo isso devidamente regulado por contrato.

O resultado esperado consistia basicamente em criar um sistema que pudesse integrar as diferentes fontes de informação em tempo real e gerar a tomada de decisão de estocagem e recuperação, disponível no nível operacional, a cada turno, o que foi um resultado atingido de forma inequívoca, conforme citado no item 3 deste trabalho.

* Contribuição técnica ao 18Seminário de Automação e TI Industrial, 23 a 26 de setembro de 2014, São Paulo, SP, Brasil. 
O desafio foi cumprido com a homologação do contrato de risco e aderência do sistema à rotina operacional, e deverá passar por fases futuras, como acontece com a implantação de novas tecnologias.

As principais dificuldades, endereçadas logo no início do projeto, foi viabilizar um sistema que pudesse gerar um resultado de estocagem e recuperação confiável e principalmente em tempo hábil.

Os primeiros testes nos levaram a resultados que levavam até 24 horas de processamento de um Micro Computador, dado a complexidade dos cálculos. Atualmente, após 2 anos, os resultados são gerados em poucos segundos.

Obviamente a descrição dos cálculos em si é protegida por registros de propriedade junto ao INPI, porém as técnicas aplicadas são descritas nos itens anteriores.

A grande dificuldade então para otimizar o Sistema e transformá-lo em uma ferramenta operacional era entender o processo do cliente, que passava por diferentes áreas, Qualidade, Operação e Manutenção. A obtenção destas informações não era tarefa fácil, pois diferentemente de um projeto típico de automação era necessário o envolvimento de todas as áreas operacionais da empresa de forma intensiva.

O projeto foi conduzido pela Gerência responsável pela Qualidade, o que foi um fator fundamental para o sucesso do projeto.

Após o passo de entender o processo em detalhes, colocava-se outro desafio que era transformar este conhecimento em aplicação de software.

Outro desafio, vivido até hoje e que deverá ser superado nas próximas fases do projeto é cultural, pois um Sistema de Gerenciamento de pátio transforma a forma como as operações são realizadas, já que elimina uma série de procedimentos manuais, propiciando ganhos por um lado, mas reduzindo a flexibilidade existente em um processo Manual. A operação poderá realizar o processo manual como era feito antes, mas terá um Sistema que poderá comparar sua decisão ao cálculo gerado pelo Sistema.

\section{RESULTADOS E DISCUSSÃO}

Para analisar os resultados do sistema web um conjunto de instâncias foi elaborado com base nas operações em diferentes períodos do complexo minerador de Carajás. Discutiremos o resultado sobre um período de 6 dias, que representam um ciclo com diferentes turnos de operação.

Uma série de análises sobre os resultados podem ser realizadas, neste trabalho optamos por exibir os ganhos da otimização em termos de deslocamento de máquinas, comparado as decisões realizadas nos mesmos dias.

Como a função objetivo do problema apresenta um conjunto de parcelas distintas, resolvemos estabelecer dois subconjuntos: o conjunto de parcelas que determinam a redução da movimentação de deslocamento de máquinas e as parcelas que buscam minimizar o desvio de qualidade em relação às demandas estabelecidas. Dessa forma os testes foram realizados determinando maior peso para as parcelas de redução de deslocamento ou a redução dos desvios de qualidade.

\footnotetext{
* Contribuição técnica ao $18^{\circ}$ Seminário de Automação e TI Industrial, 23 a 26 de setembro de 2014, São Paulo, SP, Brasil.
} 


\section{AUTOMAÇÃO \& TI}

\section{Deslocamento Total (metros)}

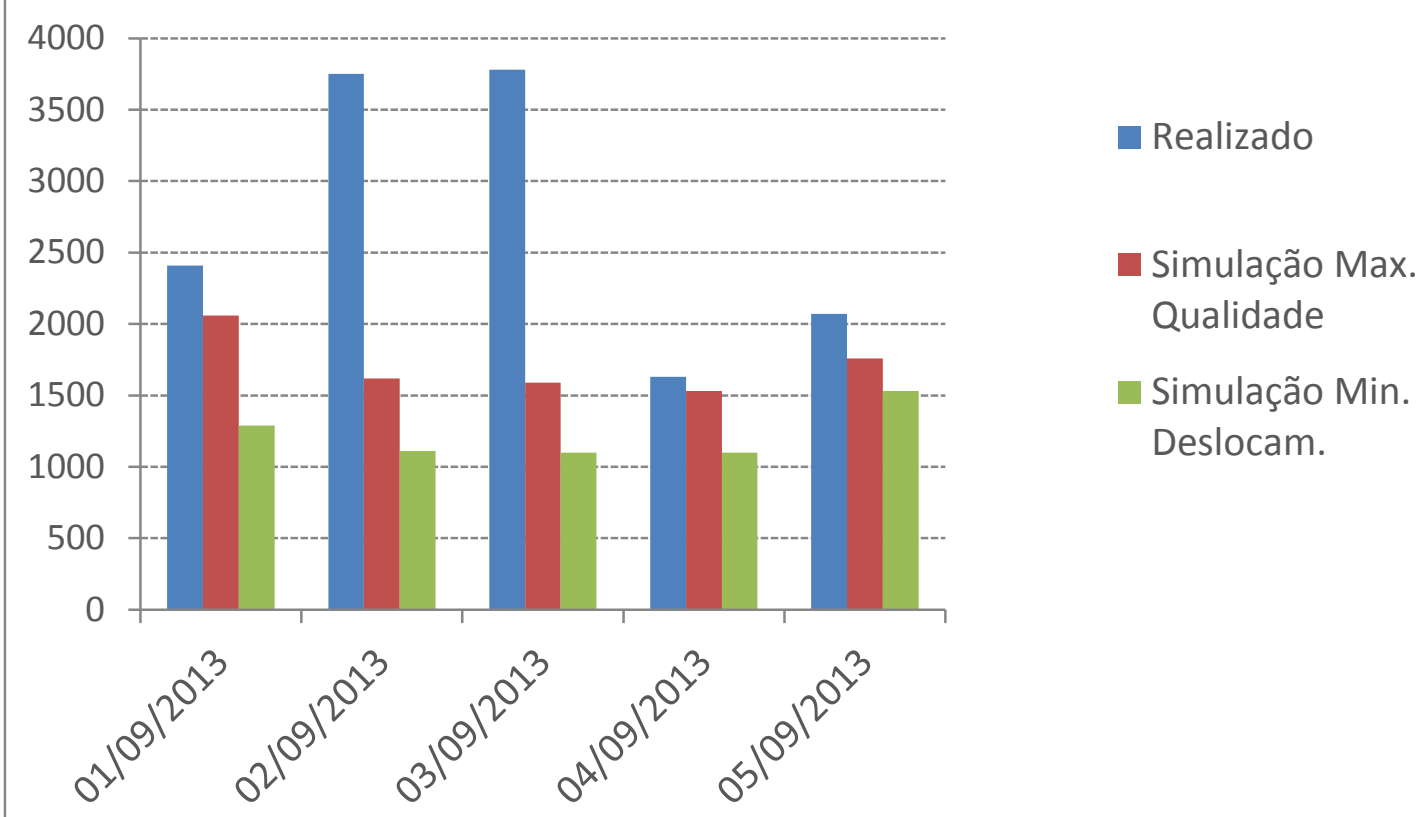

Figura 5: Deslocamento realizado pelo modelo matemático e realizado manualmente

Pelo resultado apresentado acima verificamos que o modelo apresenta ganhos de movimentação, seja priorizando a qualidade ou apenas a movimentação, quando comparados as decisões tomadas pelos operadores.

Esses resultados são preliminares, dado o estágio embrionário do estudo do problema, mas já demonstram ganhos que, acumulados ao longo de um período maior, são muito significativos.

A razão destes ganhos reside principalmente no fato de as decisões manuais não poderem analisar um horizonte de tempo maior do que poucas horas e pela rotina carregada de trabalho dos mesmos, além do que decisões manuais são basicamente empíricas não sendo capazes de analisar um conjunto de dados e previsões muito extenso.

Entretanto, análise do resultado vai muito além de quantificar os ganhos de um período, visto que se trata de uma nova fronteira de automação que foi implantada e testada exaustivamente. Conceitualmente estamos automatizando uma etapa do processo que no mundo inteiro é realizado de forma manual, que é a definição dos planos de estocagem em função das demandas e do ritmo de produção atual.

O processo que envolve as máquinas e os equipamentos passou por evoluções nas últimas décadas, com a introdução de controladores em substituição aos painéis de relés, dispositivos inteligentes integrados em redes, rápida evolução do hardware e software, entre outros.

Mesmo com tantos recursos, a definição dos planos de estocagem depende diretamente da intervenção humana, pois os apontamentos são manuais através de informação de operadores que visitam os pátios e passam as informações por rádio, são utilizadas planilhas distribuídas entre os usuários e a definição varia de acordo com o turno ou equipe de operação. As metas são uniformes, mas a forma como cada equipe desempenhará é extremamente dependente de cada equipe, pois o cenário envolvido para a tomada de decisão é muito complexo e leva em consideração uma série de variáveis.

* Contribuição técnica ao 18Seminário de Automação e TI Industrial, 23 a 26 de setembro de 2014, São Paulo, SP, Brasil. 
O resultado inegável já atingido, após vários meses de utilização do sistema pode ser comparado a substituição dos painéis de relés por controladores, visto que com a utilização de um sistema estruturado temos a documentação dos cenários e as respectivas tomadas de decisões, amparadas agora em cálculos matemáticos e coleta automática de dados em vez de informações via rádio ou telefone.

Se formos nos ater ao resultado numérico, os gráficos apresentados demonstram um potencial muito significativo, mas os próximos desafios, após a implantação "técnica" do projeto é transformar o uso do sistema em procedimento operacional, afim de perenizar os primeiros ganhos medidos que foram analisados ainda sob um período pequeno.

O termo embrionário citado na discussão do resultado refere-se à definição numérica dos ganhos do projeto, que poderá variar de acordo com a sua utilização, mas o principal resultado deste projeto nesta fase é concreto e definitivo, consiste na automação de uma etapa crítica do processo, já testada e em uso, que possibilitará saltos de qualidade no futuro.

Claro que o montante dos ganhos em longo prazo dependerá de como a tecnologia é usada, mas automação em si do processo de decisão baseado em dados coletados em tempo real e algoritmos, com possibilidade de rastreabilidade, já representa um resultado indiscutível.

\section{CONCLUSÃO}

Os resultados do trabalho demonstram que a aplicação de um modelo de otimização linear inteira-mista é viável do ponto de vista operacional e apresenta ganhos em relação as decisões que em geral são tomadas. O sistema de gerenciamento de pátios permite que as situações verificadas diariamente possam ser inseridas e refletidas no modelo resultando em decisões com alto potencial de ganho tendo em vista a complexidade do cenário. Os ganhos decorrem mesmo com os erros de previsão, pois se comparados às decisões do homem são ainda muito mais precisas.

A utilização então de técnicas de otimização descritas acima, com atualização em tempo real , representa uma nova fronteira tecnológica para as rotinas de operação na área da Mineração, visto que apesar da evolução da automação dos processos e equipamentos,o processo decisório ainda é muito pessoal e dependente de informações verificadas e lançadas manualmente.

\section{Agradecimentos}

Agradeçemos à toda equipe que trabalha há 4 anos na TSA com este assunto e a toda equipe e Gerência da VALE em Carajás, principalmente o Engenheiro Marco Aurélio, que possibilitou transformar toda a base teórica em aplicação prática, rompendo paradigmas e assumindo uma posição de vanguarda na indústria de Mineração.

\section{REFERÊNCIAS}

1 Informações e análises da economia mineral brasileira. 7ª̣ edição. 2012. Instituto Brasileiro de Mineração.

2 Bradley SP, Hax AC, Magnanti TL. Applied Mathematical Programming. AddisonWesley Publishing Company. 1977.

* Contribuição técnica ao 18Seminário de Automação e TI Industrial, 23 a 26 de setembro de 2014, São Paulo, SP, Brasil. 
3 Everett JE. Modeling of an iron ore operation to enable informed planning. Simulation Interdisciplinary Journal of Information, Knowledge, and Management. 2010. 5:101-114.

4 Everett JE. Planning an iron ore mine:from exploration data to informed mining decisions. Issues in Informing Science and Information Technology. 2013. 10:145-162.

5 Dimitrakopoulos RG, Sabour SAA. Evaluating mine plans under uncertainty: Can the real options make a diference?. 2007. Resources Policy. 3:116-125.

6 Lerchs H, Grosmann LF. Optimal design of open-pit mines. Transactions, Canadian Mining and Metallurgical Bulletin. 1965. LXVIII:17-24.

7 Fukasawa R, Aragão MVP, Porto O, Uchoa E. Solving the freight car flow problem to optimality. Electronic Notes in Theoretical Computer Science. 2002. 66(6): 42-52.

8 Drumond FP. Sistema de apoio à decisão para planejamento da produção de um terminal portuário [Dissertação de mestrado], Departamento de Ciência da Computação, Universidade Federal de Minas Gerais; 1998.

9 Costa FP, Souza MJF, Pinto LR. Um modelo de programação matemática para alocação estática de caminhões visando ao atendimento de metas de produção e qualidade. Revista Escola de Minas. 2005. 78:77-81.

10 Vieira P, Neto LE, Bessa E, Gomide F. Railway dispatch planning and control. 18th International Conference of the North American Fuzzy Information Processing Society. 1999.

11 Moraes EF, Carmo BAJM, Souza MJF, Cabral IE, Martins AX. Um modelo de programação matemática para otimizar a composição de lotes de minério de ferro da mina cauê da cvrd. Revista Escola de Minas, 59: 299-306.

12 Pimentel BS. Modelos e algoritmos para planejamento integrado na indústria da mineração [Tese de doutorado]. Departamento de Ciência da Computação da Universidade Federal de Minas Gerais. 2011.

13 Toffolo TAM. Otimização do fluxo de produtos em uma empresa mineradora [Dissertação de mestrado]. Departamento de Ciência da Computação da Universidade Federal de Minas Gerais. 2009.

14 Almeida FA, Pimentel BS. Um modelo matemático para o problema de programação integrada de curto prazo em minas. XLII Simpósio Brasileiro de Pesquisa Operacional, Bento Gonçalves, Brasil. 2010.

* Contribuição técnica ao $18^{\circ}$ Seminário de Automação e TI Industrial, 23 a 26 de setembro de 2014, São Paulo, SP, Brasil. 